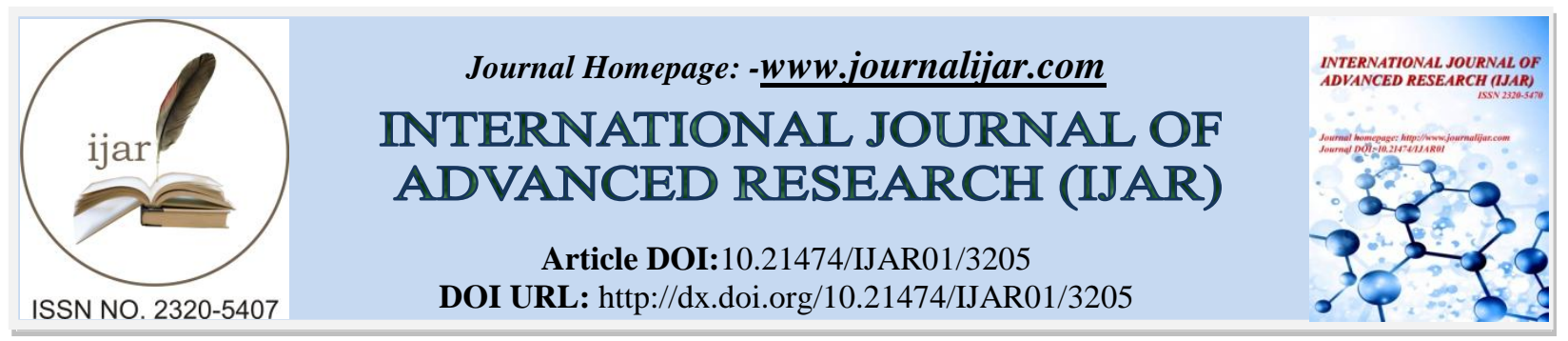

RESEARCH ARTICLE

\title{
SHORT TERM OUTCOME OF REDO MITRAL VALVE SURGERY: EMERGENCY VERSUS ELECTIVE.
}

Ali Emad, Ashraf Abdel Aziz, Tamer Elbanna, Mostafa Mansy and Amr Elprince.

M.D. Cardiothoracic surgery, National Heart Institute, Egypt.

\section{Manuscript Info}

Manuscript History

Received: 23 December 2016

Final Accepted: 14 January 2017

Published: February 2017

\section{Abstract}

Background: With advances in medical therapy and life expectancy, reoperation to replace dysfunctional mechanical heart valve prosthesis is an increasingly common procedure and there have been gradual decreases in perioperative risk for redo valve surgery over the past 2 decades

Aim of the work: The aim of this study was to investigate the overall outcome of adult patients undergoing redo-mitral valve replacement (redo-MVR).

Patients and Methods: forty cases had previous mitral valve replacement were admitted for redo mitral valve replacement. They were divided into two groups:

Group (A): (Twenty cases) were admitted as emergency cases from the ER.

Group (B): (Twenty cases) were admitted from out patient clinic as elective cases.

Results:The hospital mortality was (20\%). There was no effect regarding age, sex, cardiac rhythm, number of previous operations, type of the previous prosthesis, and interval from last implantation. Taking in consideration that mortality was higher with emergency group (15\%).

Conclusion: pre operative parameters of morbidity and mortality that showed higher incidence in emergency group were:NYHA functional class, LVEDD, LVESD dimensions, Redo cardiac surgery, Infective endocarditis, left ventricular dysfunction EF less than 35 .

\section{Introduction:-}

Since the first valve replacements in the 1950s, major advances have been made in mitral valve (MV) surgical technique, prosthesis design and peri-operative care. Improved survival has inevitably meant that more patients require redo-MVR during follow-up. However, redo surgery may be associated with significant risk, which must be balanced against the benefits to the patient. Avoiding the complications of redo-sternotomy such as injury to prior grafts and haemorrhage must be taken in consideration. (Khan \& Younan, 2009). Patients undergoing valve reoperations have a diverse and complex clinical profile. Thrombi may form on mechanical valves and cause orifice obstruction, leaflet malcoaptation, and acute valvular dysfunction (Tang, et al., 2007; Mahesh, et al., 2005). So, redo valve surgery is associated with a higher operative mortality rate than first time valve surgery and certain risk 
factors may be preventable(Tang, et al., 2007; Rankin, et al., 2006). With advances in medical therapy and life expectancy, reoperation to replace dysfunctional mechanical heart valve prosthesis is an increasingly common procedure and there have been gradual decreases in perioperative risk for redo valve surgery over the past 2 decades, likely due to increased surgical experience, better myocardial protection, and improved patient management. However, mortality rates remain higher than first-time valve replacement surgery(Rankin, et al., 2006; Borger, et al., 2002). Several studies have been studying the predictors of mortality during reoperative valve surgery (Rankin, et al., 2006; Borger, et al., 2002).

Aim of work:- The aim of this study was to investigate the overall outcome of adult patients undergoing redomitral valve replacement (redo-MVR).

\section{Patients and Methods:-}

Forty cases had previous mitral valve replacement were admitted for redo mitral valve replacement. They were divided into two groups: Group (A): (Twenty cases) were admitted as emergency cases from the ER. Group (B): (Twenty cases) were admitted from out patient clinic as elective cases. All patients were opened through median sternotomy and cardiopulmonary bypass with aorto-bicaval cannulation. A mechanical valve is inserted with horizontal mattress pledgeted non absorbable sutures.

\section{Inclusion criteria:-}

surgery for prosthetic endocarditis. Surgery for para-valvular leak. Surgery for structural valve degeneration. Surgery for prosthetic valve thrombosis .

\section{Exclusion criteria:-}

Impaired renal or liver functions. previous cerebro-vascular disease. impaired respiratory functions( eg. Chronic obstructive pulmonary disease, emphysema, suppurative lung disease, etc..) concomitant coronary artery disease or aortic valve disease
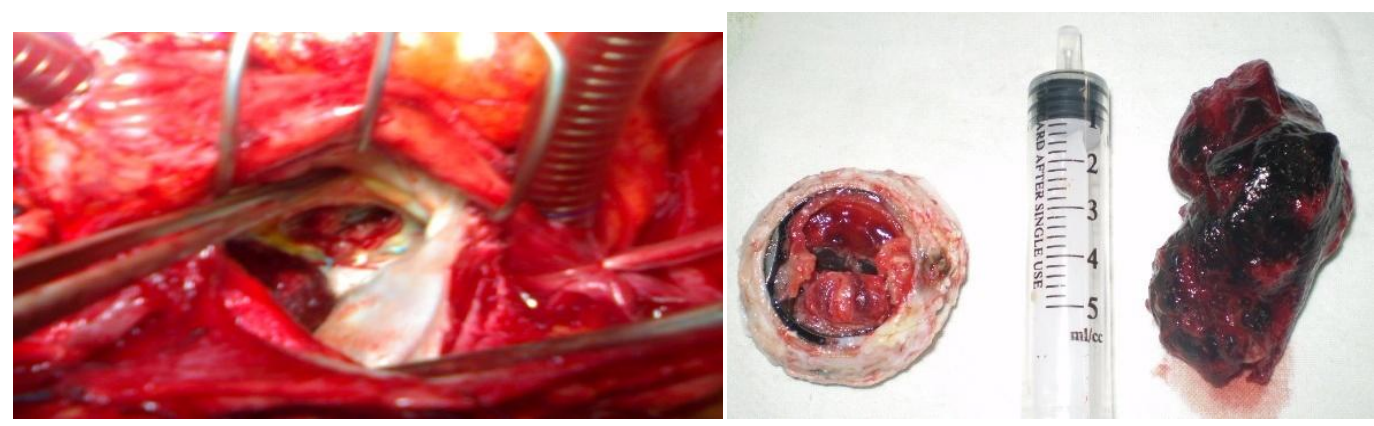

Figure 1:- A showing intraoperative view of a stuck mitral valve prosthesis. \& B showing a thrombus obstructing the mitral valve with a large left trial thrombus .

\section{Statistical analysis:-}

patients categorical predictor variables and outcomes were analyzed using Pearson Chi-Square $\left(\chi^{2}\right)$ test for Independence. Statistical analysis was performed using Microsoft ${ }^{\circledR}$ Office Excel 2010 and SPSS (Version 20, 2011). $P$ value $<0.05$ was considered statistically significant.

\section{Results:-}

Forty cases underwent redo mitral valve replacement in department of cardiac surgery in National Heart Institute and cairo university in the period between November 2012 and November 2014 after obtaining local ethical approval. There were 17 males (42.5\%) and 23 females (57.5\%), the age ranged between 22 and 58 years with a mean of 40 years. The predominant NYHA score classification was (II) $=13$ patient $(32.5 \%)$, followed by (I)=11 patient $(27.5 \%)$ , then $(\mathrm{III})=10$ patients $(20 \%)$, and finally $(\mathrm{IV})=6$ patients $(15 \%)$. Considering hemo-dynamics 5 patients were unstable $(12.5 \%), 5$ patients arrived operation room (OR) shocked with pale cold skin, low urine output, tachypnic, tachycardic and reduced conscious level, 30 patients were stable (75\%), 5 patients were on inotropes $(12.5 \%)$. Regarding number of previous mitral valve replacement 33 patients $(82.5 \%)$ had previous mitral valve replacement once before, 6 patients $(15 \%)$ had it twice, 1 patient $(2.5 \%)$ had it thrice. 
Table 1:- showing demographic data of the patients,

\begin{tabular}{|c|c|c|}
\hline (2) & Elective MVR & Emergency MVR \\
\hline Age (span) & $24-55$ & $22-58$ \\
\hline Gender & 11 male/ 9 female & 6 male/14 female \\
\hline 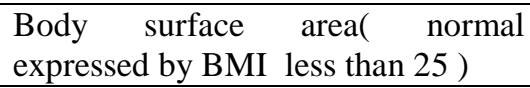 & 18 normal/ 2 over wt & 19 normal /1 over wt \\
\hline Euro score II & $(2-30 \%)$ & $(15-60 \%)$ \\
\hline NYHA score & $\begin{array}{l}\mathrm{I}=>11 \\
\mathrm{II}=>5 \\
\mathrm{III}=>4 \\
\mathrm{IV}=>0\end{array}$ & $\begin{array}{l}\mathrm{I}=>0 \\
\mathrm{II}=>8 \\
\mathrm{III}=>6 \\
\mathrm{IV}=>6\end{array}$ \\
\hline $\begin{array}{l}\text { Previous MVR } \\
\text { Once } \\
\text { Twice } \\
\text { Thrice } \\
\text { Bioprosthesis } \\
\text { Mechanical } \\
\end{array}$ & $\begin{array}{l}18 \\
2 \\
0 \\
1 \\
19 \\
\end{array}$ & $\begin{array}{l}15 \\
4 \\
1 \\
0 \\
20 \\
\end{array}$ \\
\hline Time to re-operation & (2 month- 19.5 year) & (6 month- 15 year) \\
\hline $\begin{array}{l}\text { Indications for re-operation } \\
\text { Thrombosis } \\
\text { Paravalvular leak } \\
\text { Endocarditis } \\
\text { Degenerative }\end{array}$ & $\begin{array}{l}14 \\
5 \\
0 \\
1\end{array}$ & $\begin{array}{l}12 \\
4 \\
4 \\
0\end{array}$ \\
\hline Hemodynamic stability & 20 stable & $\begin{array}{lc}10 & \text { stable } \\
5 & \text { on inotrope } \\
4 \quad \text { shocked } & \\
1 \quad \text { shocked and arrested with } \\
\text { induction }\end{array}$ \\
\hline
\end{tabular}

Indications for re-operation were thrombosis in 26 patient $(65 \%)$, paravalvular leak in 9 patients $(22.5 \%)$, endocardidtis in 4 patients $(10 \%)$ and degenerative 1 patient $(2.5 \%)$.Considering preoperative echo data : ejection fraction varies from (40-72\%), and 2 cases were below than $50 \%$.

Table 2:- pre-operative ejection fraction

\begin{tabular}{|l|l|l|l|}
\hline Pre-op Ejection fraction & Elective & Emergency & Total \\
\hline Good $(>\mathbf{5 0 \%})$ & 18 & 8 & 26 \\
\hline Moderate(<50\% and $\mathbf{5 2 5})$ & 2 & 7 & 9 \\
\hline Poor $(<\mathbf{2 5 \% )}$ & 0 & 0 & 0 \\
\hline Total & 20 & 15 & 35 \\
\hline
\end{tabular}

Table 3:- showing preoperative data.

\begin{tabular}{|l|l|l|}
\hline & Elective MVR & Emergency MVR \\
\hline Ejection fraction & $\begin{array}{l}(42-72 \%) \\
18 \text { cases above 50\% } \\
2 \text { cases below 50\% }\end{array}$ & $\begin{array}{l}(40-62 \%) \\
5 \text { cases were not assessed pre } \\
\text { operative }\end{array}$ \\
\hline LVESD & $(2.6-4.9)$ & $(2.5-4.6)$ \\
\hline LVEDD & $(4.9-7.9)$ & $(4.7-8.0)$ \\
\hline Tricuspid regurge & $\begin{array}{l}17 \text { severe TR } \\
3 \text { moderate TR }\end{array}$ & $\begin{array}{l}14 \text { severe TR } \\
\text { moderate TR } \\
5 \text { cases were not asses }\end{array}$ \\
\hline Atrial thrombus & 14 cases & 12 cases \\
\hline Gradient (max) & $(11-23) \mathrm{mmhg}$ & $\begin{array}{l}(16-26) \mathrm{mmhg} \\
(9-18)\end{array}$ \\
Gradient (mean) & $(6-14) \mathrm{mmhg}$ & $(0.4-2.6) \mathrm{cm}$ \\
\hline Mitral valve area (cm2) & $(0.3-2.7) \mathrm{cm}$ & $(25-85) \mathrm{mmhg}$ \\
\hline Systolic pulmonary artery pressure & $(20-74) \mathrm{mmhg}$ & \\
\hline
\end{tabular}


Tricuspid regurge was found in all pre operative assessed cases, severe tricuspid regurge in 31 patients $(77.5 \%)$ and moderate tricuspid regurge 4 cases (10\%). Atrial thrombus was found in 26 patients $(65 \%)$. Prosthetic valve gradient varied from $(11-26 \mathrm{mmHg})$ as maximum gradient, and $(6-18 \mathrm{mmHg})$ as mean gradient. Mitral valve area ranged from $(0.3-2.7 \%) \mathrm{cm} 2$.systolic pulmonary artery pressure ranged from $(20-85 \%) \mathrm{mmHg}$.

Table 4:- showing .Intra operative and immediate post operative events

\begin{tabular}{|c|c|c|}
\hline & Elective MVR & Emergency MVR \\
\hline Cross clamp time & $(55-145) \min$ & $(65-185) \min$ \\
\hline Cardio pulmonary bypass time & $(75-240) \min$ & $(90-260) \min$ \\
\hline Concomitant procedure & 20 de vega & 16 de vega \\
\hline Type of prosthesis settled & $\begin{array}{ll}\text { Monleaflet } 1 \\
\text { Bileaflet } 18 \\
\text { Bioprothesis } 1 \\
\end{array}$ & $\begin{array}{l}\text { Ball and cage } 1 \\
\text { Bileaflet } 19\end{array}$ \\
\hline Blood loss & 2 cases Catastrophic blood loss & 4 cases catastrophic blood loss \\
\hline Pace maker device intra operative & 3 cases & 3 cases \\
\hline Haemo filtration need & 12 cases & 15 cases \\
\hline Intra operative mortality & 1 case & 4 cases \\
\hline First two day ICU mortality & 1 case (poor LV function) & 2 cases (poor LV function) \\
\hline Re opening $\left(2^{\text {nd }} l\right.$ look $)$ & 1 case (bleeding) & 1 case ( open chest) \\
\hline Prolonged ICU stay (> 7 days) & $\begin{array}{cl}2 \text { cases } & \\
1 & \text { (chest infection) } \\
1 & \text { ( weaning inotrope) }\end{array}$ & $\begin{array}{cl}3 \text { cases } & \\
2 & \text { ( chest infection) } \\
1 & \text { (weaning inotrope) }\end{array}$ \\
\hline Need for dialysis & 0 & 1 case \\
\hline
\end{tabular}

Considering intra operative and immediate post operative data:-

Cross clamp time is a little bit shorter in elective cases (55-145) min compared to (65-185)min for emergency cases, and bypass time goes with the same sequence (75-240) min for elective cases and (90-260) min for emergency cases. Prosthetic valve types were as following; 1 patient $(2.25 \%)$ with monoleaflet valve, 1 patient $(2.25 \%)$ with ball and cage , 1 patient (2.25\%) with bioprothesis , most of cases were bileaflet 37 patient $(92.5 \%)$. Intra operative events includedCatastrophic blood loss occurred in 6 patients (15\%). Epicardial lead temporary pacemaker was needed in 6 patients (15\%) also, most of cases needed hemofiltration 27 patients (67.5\%). Intra operative mortality were 1 case $(2.25 \%)$ for elective cases and 4 cases (10\%). hospital mortality was 1 case $(2.25 \%)$ for elective cases and 2 cases for emergency cases due to poor contractility. $2^{\text {nd }}$ look was needed for 1 case in elecective cases due to bleeding, and 1 case for emergency (open chest ).Considering post operative data :Permenant pacemaker was needed for 1 case. Residual infective endocardidtis remained in 1 case (fungal type). 1 case had cardiac tamponade (patient was discharged and came back 3 week later to emergency department with severe dyspnea, echo revealed massive effusion that was drained with subxiphoid incicsion )and 1 case left hospital with lt side hemiparesis.

(It is worth saying that these complications occurred in the emergency group.)Considering post operative 6 month echo data : Ejection fraction improved in most of cases, also left ventricle dimensions. Residual tricuspid regurge in 6 patients $(15 \%)$ of each group a sum of 12 patients (30\%). Gradients also decreased in all patients, maximum gradient ranged from (6-12) $\mathrm{mmHg}$ for elective group , and almost the same for emergency group (6-14) $\mathrm{mmHg}$. Also mitral valve area ranged from $(1.8-3.1) \mathrm{cm} 2$ for both groups.Elective cases had a much better outcome considering mortality ( 2 cases for elective group compared for 6 cases for emergency group) and morbidities. 
Table 5:- showing statistical analysis of data.

\begin{tabular}{|c|c|c|c|c|}
\hline & Group & $\mathrm{N}$ & Mean & Std. Deviation \\
\hline \multirow[t]{2}{*}{ Age } & Elective & 20 & 37.55 & 10.445 \\
\hline & Emergency & 20 & 37.65 & 9.986 \\
\hline \multirow[t]{2}{*}{ BMI } & Elective & 20 & 22.100 & 4.0503 \\
\hline & Emergency & 20 & 22.475 & 3.2024 \\
\hline \multirow[t]{2}{*}{ Euro score II } & Elective & 20 & 18.400 & 9.4000 \\
\hline & Emergency & 20 & 28.900 & 11.3000 \\
\hline \multirow[t]{2}{*}{ EF-Pre } & Elective & 20 & 59.70 & 7.794 \\
\hline & Emergency & 15 & 51.20 & 6.678 \\
\hline \multirow[t]{2}{*}{ LVEDD-Pre } & Elective & 20 & 3.350 & 0.7688 \\
\hline & Emergency & 15 & 3.620 & 0.6858 \\
\hline \multirow[t]{2}{*}{ LVEDD-Pre } & Elective & 20 & 6.975 & 0.7552 \\
\hline & Emergency & 15 & 7.060 & 0.7917 \\
\hline \multirow[t]{2}{*}{ Max Grad-Pre } & Elective & 20 & 19.25 & 3.370 \\
\hline & Emergency & 20 & 21.25 & 3.193 \\
\hline \multirow[t]{2}{*}{ Mean Grad.-Pre } & Elective & 15 & 9.93 & 2.463 \\
\hline & Emergency & 15 & 13.33 & 2.610 \\
\hline \multirow[t]{2}{*}{ MVA-Pre } & Elective & 20 & 1.610 & 0.6112 \\
\hline & Emergency & 15 & 1.540 & 0.5667 \\
\hline \multirow[t]{2}{*}{ SPAP } & Elective & 20 & 52.70 & 15.644 \\
\hline & Emergency & 15 & 58.53 & 17.952 \\
\hline \multirow[t]{2}{*}{$\mathrm{CCT}$} & Elective & 20 & 105.75 & 24.777 \\
\hline & Emergency & 16 & 122.19 & 31.831 \\
\hline \multirow[t]{2}{*}{ CPB time } & Elective & 20 & 166.00 & 45.900 \\
\hline & Emergency & 16 & 174.06 & 46.304 \\
\hline \multirow[t]{2}{*}{ EF-Post } & Elective & 18 & 63.89 & 6.623 \\
\hline & Emergency & 14 & 56.14 & 6.815 \\
\hline \multirow[t]{2}{*}{ LVESD-Post } & Elective & 18 & 3.250 & 0.6819 \\
\hline & Emergency & 14 & 3.393 & 0.5797 \\
\hline \multirow[t]{2}{*}{ LVEDD-Post } & Elective & 18 & 6.294 & 0.8599 \\
\hline & Emergency & 14 & 6.271 & 0.6999 \\
\hline \multirow[t]{2}{*}{ Max Grad-Post } & Elective & 18 & 7.83 & 1.917 \\
\hline & Emergency & 14 & 10.50 & 2.139 \\
\hline \multirow[t]{2}{*}{ Mean Grad-Post } & Elective & 18 & 5.28 & 1.018 \\
\hline & Emergency & 14 & 5.64 & 1.393 \\
\hline \multirow[t]{2}{*}{ MVA-Post } & Elective & 18 & 2.517 & 0.3312 \\
\hline & Emergency & 14 & 2.593 & 0.3407 \\
\hline
\end{tabular}

Table 6:- Procedure delayed (6 m) Echographic characteristics.

\begin{tabular}{|l|l|l|}
\hline & Elective MVR & Emergency MVR \\
\hline Ejection fraction & $\begin{array}{l}(50-76 \%) \\
20 \text { cases above 50\% }\end{array}$ & $\begin{array}{l}(46-70 \%) \\
12 \text { cases above 50\% }\end{array}$ \\
\hline LVESD & $(2.5-4.9)$ & $(2.5-4.5)$ \\
\hline LVEDD & $(4.6-7.4)$ & $(4.7-7.1)$ \\
\hline Tricuspid regurge & 6 cases ( mild to moderate) & 6 cases ( mild to moderate) \\
\hline & & $\begin{array}{l}(6-14) \mathrm{mmhg} \\
(4-8)\end{array}$ \\
\hline $\begin{array}{l}\text { Gradient (max) } \\
\text { Gradient (mean) }\end{array}$ & $\begin{array}{l}(6-12) \mathrm{mmhg} \\
(3-7) \mathrm{mmhg}\end{array}$ & $(1.8-3.1) \mathrm{cm}$ \\
\hline Mitral valve area (cm2) & $(1.8-3.0) \mathrm{cm}$ & $(25-73) \mathrm{mmhg}$ \\
\hline & & \\
\hline Systolic pulmonary artery pressure & $(20-60) \mathrm{mmhg}$ & \\
\hline
\end{tabular}


Table 7:- Procedure related mortality

\begin{tabular}{|l|l|l|}
\hline & Elective MVR & Emergency MVR \\
\hline Inta operative mortality & 1 case & 4 cases \\
\hline ICU mortality & 1 case & 2 case \\
\hline Delayed $(6$ m) mortality & 0 & 0 \\
\hline Over all mortality & 2 cases & 6 cases \\
\hline
\end{tabular}

\section{Discussion:-}

The reported mortality risk of elective re-operation may be as low as $5.4 \%$ to $11 \%$, while, for emergency procedures, it could be as high as 38 to $61.5 \%$.. Replacement operations in emergency cases are generally performed in a functionally compromised group of patients, so these patients tolerate complications poorly in comparison to elective cases. \{FormattingCitation\}(Sampath Kumar et al., 2002; Wauthy, Goldstein, Demanet, \& Deuvaert, 2003). Nevertheless, there is evidence that clinical outcomes following redo-valve surgery have improved especially in emergency cases owing to advancement in cardiac critical care units (Vohra et al., 2012).In particular, it is necessary to identify the perioperative variables (including technical complications and the patients' preoperative condition in both emergency and elective cases) in order to offer patients the most appropriate interventions. (Vohra et al., 2012). .In this study, the overall hospital mortality was 8 patients (20\%), (2 cases for elective group (5\%) one intra operative mortality and one ICU mortality compared to 6 cases for emergency group $(15 \%)$ with four cases intra operative mortality and two cases ICU mortality) .Brandao et al reported a hospital mortality of $10.9 \%$ for emergency redo cases.(de Almeida Brandão et al., 2002). In another study done in 2002 , Kumar and associates reported mortality of $11 \%$ in emergency redo mitral valve operation (Sampath Kumar et al., 2002). Overall operative mortality was $8.4 \%$ in elective redo mitral operations (Beghi et al., 2002). Wauthy et al. observed in elective redo valve surgery a mortality rate of $8 \%$ (Wauthy et al., 2003). Such difference in mortality may be; as mentioned by Wauthy, related to technological evolutions of cardiac critical care units (e.g. defibrillation patches,improved ECC technology, the use of ECMO, the Cell Saver, etc.) and increased surgical experience.In this study, mortality in relation to NYHA classification were 2 cases (5\%) from the elective group NYHA III, while it was 6 cases $(15 \%)$ for emergency group (5 cases $(12.5 \%)$ NYHA IV) and (1 case $(2.5 \%)$ NHYA III). NYHA functional class IV was also a risk factor in short term survival as mentioned by Akay and associates and others in many studies (Akay et al., 2008). Our conclusion regarding NYHA classification as a statistically significant factors for mortality in both groups. Vohra et al also confirmed that New York Heart Association functional class was highly significant for operative mortality; as operative mortality in their study was $4 \%$ for functional classes (I through III), and 19\% for functional class (IV), they reported NYHA functional class as an important risk factor for hospital mortality. NYHA FC is considered as the most frequently quoted risk factor associated with death in redo valve surgery. This was due to that mortality in their study reached up to $30 \%$ with stage IV (half cases were emergency) compared to less than $10 \%$ in stage II and III (all cases were elective).(Vohra et al., 2012). Considering morbidities, reopening was done in 1 case (2.5\%) for elective group and 1 case $(2.5 \%)$ that was left open chest for emergency group. This morbidity was not statistically significant between the two groups. Akay and associates reported bleeding in 5.6\% of his patients with equal incidence for both emergency and elective cases (Akay et al., 2008). Pother et al had excessive postoperative bleeding (more than $1,000 \mathrm{~mL}$ in the first 24 postoperative hours) occurred in $14.5 \%$ (9\% were for emergency group) of patients while re-exploration was done in only $8 \%$ of them(Potter et al., 2004). In this study, need for dialysis 1 case (2.5\%) due to constant rising creatinine and potassium levels in emergency group. 6 cases $(15 \%)$ had renal dysfunction 4 cases in emergency group (10\%) and 2 cases in elective group (5\%) in form of rising creatinine level that responded to diuretics and drug dose adjustment. Akay and associates reported $14.2 \%$ with postoperative renal dysfunction $10 \%$ for emergency group (Akay et al., 2008). Preoperative renal impairment, CVS, prolonged bypass time and cross clamp time are risk factors for postoperative renal dysfunction. In this study, permenant pacemaker was installed in 1 case $(2.5 \%)$ in emergency group due to complete heart block that did not recover after 14 days. This morbidity was not statistically significant between the two groups. Pother et al had complete heart block and brady arrhythmia in $3 \%$ of cases of redo mitral valve surgery only $0.3 \%$ of cases needed premenant pacemaker (one case after redo aorta and mitral ).(Potter et al., 2004). In this study, cerebrovascular accident (inform of left hemiparesis) was noticed in 1 case $(2.5 \%)$ in emergency group. Hemodynamic instability and disturbed conscious level in absence of evidence of stroke were noticied in 5 patients (12.5\%) in emergency group with 1 case $(2.5 \%)$ that arrested with induction . this makes this parameter of statistically significance between the two groups. Potter in his study in 2004 documented $2.8 \%$ stroke in patients with repeated mitral valve replacement $(75 \%$ of cases occurred in emergency cases. (Potter et al., 2004). Residual infective endocarditis evidenced by blood culture was 
noticed in 1 case (2.5) in the emergency group. This morbidity was not statistically significant between the two groups. In our study the cause of this prolonged time for bypass was in most cases due to extra time needed for circulatory support due to associated left ventricular dysfunction. Mean cross clamp time for elective cases were $100 \mathrm{~min}$ and for emergency cases $125 \mathrm{~min}$, as for bypass time were $157.5 \mathrm{~min}$ and $175 \mathrm{~min}$ respectively. This was not statistically significant for both groups. McGrath et al stated that long bypass time and long cross clamp time are predictors of mortality (Wauthy et al., 2003). Brandão mentioned that among the intraoperative variables associated with higher hospital mortality was Cross clamp time longer than $120 \mathrm{~min}($ de Almeida Brandão et al., 2002). Global myocardial ischemic time alone was a strong predictor of hospital mortality in many studies. In contrary others had denied both factors as significant predictors for the hospital mortality (Potter et al., 2004). In our study, the sex (11 male, 9 female ) for elective group and (6 male, 14 female) for emergency group and age of patients mean for elective group (39.5 years) and mean for emergency group (40 years) were not statistically significant in both groups. Vohra et al showed that sex and age did not affect the outcome in both elective and emergency groups (Vohra et al., 2012). Another study done by Akay and co-workers shows that re-do cardiac surgery in patients over the age of 70 can be undertaken with acceptable operative morbidity and mortalityAdvanced age is associated with decreased physiologic reserve and increased comorbid factors. Their functional reserve capacity is diminished compared with younger patients. They confirmed that females are significantly labile to mortality than males (Akay et al., 2008). In our study thrombosis was found in 26 patient (65\%) with 14 (35\%)elective cases and 12 (30\%) emergency cases. paravalvular leak in 9 patients $(22.5 \%)$ including $5(12.5 \%)$ elective cases and $4(10 \%)$ emergency cases, endocardidtis in 4 patients (10\%) all were emergency cases and 1 elective degenerative valve case $(2.5 \%)$. Indication of reoperation had no statistically significance regarding outcome for both groups. Brandao and Vohra mentioned that the indication for surgery had no impact on in-hospital mortality (de Almeida Brandão etal., 2002; Vohra et al., 2012). According to Maciejewski et al ; operative mortality was significantly higher in those patients who reoperated because of prosthetic endocarditis (Maciejewski et al., 2011). Presence of valve infection is also a predictor ( Potter et al., 2004). Other observations suggest that the factors responsible for higher mortality are active infective endocarditis and valve thrombosis (Sampath Kumar et al., 2002). In our study Atrial fibrillation was observed in all patients $(100 \%)$, this may be attributed to the fact that the main cause of the primary surgery for valve replacement was due to rheumatic affection but its effect on hospital mortality was not significant. Atrial fibrillation has been identified as a risk factor for mortality and morbidity associated with valve surgery (Maciejewski et al., 2011), as it may cause low cardiac output during the postoperative period or predispose to thromboembolic events. In our series, atrial fibrillation was not identified as a risk factor for hospital mortality. In our study, 33 patient (82.5\%) had the operation once before (18 cases $(45 \%)$ from elective group and 15 cases $(37.5 \%)$ from emergency gropu). And 6 cases $(15 \%)$ had it twice before $(2$ cases $(5 \%)$ for elective group and 4 cases $(10 \%)$ for emergency group. 1 case $(2.5 \%)$ from elective group had it three times before. Number of prior operations did not show a significant effect on outcome on both groups. Although there was a trend to higher operative mortality with increasing number of prior cardiac operations, this factor was not significant in multivariable analysis.. Some reported that second reoperations were not more risky than first reoperations, but by the third reoperation, risks were high for all subgroups. This was confirmed by Beghi et al where the number of previous reoperations was independent determinant for reoperation (Beghi et al., 2002). Our study suggests that left ventricular dysfunction was associated with higher hospital mortality in both groups (1 case $(2.5 \%)$ for elective group and 2 cases $(5 \%)$ for emergency group). This was statistically significant. Low left ventricular ejection fraction (less than $35 \%$ ) and increased LVEDD more than $50 \mathrm{~mm}$ have been reported of significance in mortality by Akay and associates (Akay et al., 2008). According toMaciejewski et al operative mortality was significantly higher in those patients who were had impaired left ventricular function (Maciejewski et al., 2011).

\section{Conclusion:-}

Redo valve surgery is an increasingly common problem. Recent decades have seen a steady increase in the number of cases referred for redo cardiac surgery, which are associated with increased risk of morbidity and mortality compared to the first-time operations. Many studies were done to address the outcome ( mortality and morbidities) following redo mitral valve replacement. forty cases had previous mitral valve replacement were admitted for redo mitral valve replacement. They were divided into two groups: Group (A): (Twenty cases) were admitted as emergency cases from the ER. Group (B): (Twenty cases) were admitted from out patient clinic as elective cases. The hospital mortality was $(20 \%)$. There was no effect regarding age, sex, cardiac rhythm, number of previous operations, type of the previous prosthesis, and interval from last implantation. Taking in consideration that mortality was higher with emergency group (15\%). In conclusion, pre operative parameters of morbidity and mortality that showed higher incidence in emergency group were: NYHA functional class, LVEDD, LVESD 
dimensions, Redo cardiac surgery sternotomy and adhesio-lysis carries a significant risk of catastrophic bleeding especially with the rush accompanning hemodynamic instability, Infective endocarditis, left ventricular dysfunction EF less than 35. Post operative morbidities noticed in emergency group were : (cardiac tamponade, permenant pacemaker, residual infective endocarditis, need for dialysis and cerebro vascular accidents ) were not statistically significant.

\section{References:-}

1. Akay TH, Gultekin, B., Ozkan, S., Aslim, E., Uguz, E., Sezgin, A., \& Aslamaci, S.. Mitral valve replacements in redo patients with previous mitral valve procedures: mid-term results and risk factors for survival. Journal of cardiac surgery, 23(5) (2008): 415-21.

2. Beghi C, De Cicco, G., Nicolini, F., Ballore, L., Reverberi, C., \& Gherli, T.. Cardiac valve reoperations: analysis of operative risk factors in 154 patients. The J Heart Valve Dis, 11(2) (2002): 258-62.

3. Borger MA, Yau TM, Rao V, Scully HE, David TE. "Reoperative mitral valve replacement: importance of preservation of the subvalvular apparatus." Ann Thorac Surg 74 (2002): 1482-1487.

4. De Almeida Brandão CM, Pomerantzeff, P. M. A., Souza, L. R., Tarasoutchi, F., Grimberg, M., Ramires, J. A. F., \& Almeida de Oliveira, S.. Multivariate analysis of risk factors for hospital mortality in valvular reoperations for prosthetic valve dysfunction. Eur J Cardiothorac Surg : 22(6) (2002): 922-6.

5. UKhan NU, and Younan N. "does preoperative computed tomography reduce the risks associated with re-do cardiac surgery?" Interact Cardiovasc Thorac Surg 9 (2009): 119-123.

6. Maciejewski M, Piestrzeniewicz, K., Bielecka-Dąbrowa, A., Piechowiak, M., \& Jaszewski, R.. Redo surgery risk in patients with cardiac prosthetic valve dysfunction. Archives of medical science : AMS, 7(2) (2011): 2717.

7. Mahesh B, Angelini G, Caputo M, Jin XY, Bryan A. "Prosthetic valve endocarditis." Ann Thorac Surg 80 (2005): 1151-1158.

8. Potter DD, Sundt, T. M., Zehr, K. J., Dearani, J. A., Daly, R. C., Mullany, C. J., ... Orszulak, T. A.. Risk of repeat mitral valve replacement for failed mitral valve prostheses. Ann Thorac Surg, 78(1) (2004): 67-72; discussion 67-72.

9. Rankin JS, Hammill BG, Ferguson TB, Glower DD, O'Brien SM, DeLong ER, Peterson ED, Edwards FH. "Determinants of operative mortality in valvular heart surgery." Thorac Cardiovasc Surg 131 (2006): 547-557.

10. Sampath Kumar A, Dhareshwar, J., Airan, B., Bhan, A., Sharma, R., \& Venugopal, P.. Redo mitral valve surgery-a long-term experience. Journal of cardiac surgery, 19(4) (2002): 303-7.

11. Tang GHL, Maganti M, David TE, Feindel CM, Scully HE, Borger MA. "Effect of Prior Valve Type on Mortality in Reoperative Valve Surgery." Ann Thorac Surg 83 (2007): 938-945.

12. Vohra, H. A., Whistance, R. N., Roubelakis, A., Burton, A., Barlow, C. W., Tsang, G. M. K., ... Ohri, S. K.. Outcome after redo-mitral valve replacement in adult patients: a 10-year single-centre experience. Interactive cardiovascular and thoracic surgery, 14(5) (2012): 575-9.

13. Wauthy, P., Goldstein, J. P., Demanet, H., \& Deuvaert, F. E. (2003). Redo valve surgery nowadays: what have we learned? Acta chirurgica Belgica, 103(5), 475-80. 